\title{
Study on Enterprise Computer Application Technology and Information Construction
}

\author{
Li Xian-qin \\ NanChang Institute of Science \& Technology
}

\begin{abstract}
With the rapid development of computer technology and information technology, more and more enterprises start to use computer application technology and conduct information construction to improve their own competitiveness, which is the requirement of modern social market economy. The construction of computer application technology and information can effectively improve the social and economic benefits of enterprises. This paper introduces the general situation of computer application technology, and discusses the development the effect of computer application technology and the development status respectively, as well as the future development trend of computer application technology. Thus, the development of China's computer application technology is discussed in detail.
\end{abstract}

Keywords-enterprise; computer application technology; information technology

\section{INTRODUCTION}

The continuing development of science and technology in China promotes the better development of computer application technology, which plays an important role in social production and daily life. Computer applications make our daily life more convenient, enhancing computer security awareness that is important for computer applications. Therefore, it is especially important to enhance mutual cooperation of computer application technology and security maintenance. The development of computer application technology is an important guarantee to promote social progress. The paper introduces the overview of computer application technology firstly and then discusses the effect and state-of-the-art of computer application technology respectively. The future development trend of computer application technology is discussed deeply at last.
In recent years, with the continuous development of science and technology and progress, computer technology has been greatly improved compared with the past and its role in enterprise development has become increasingly important. Currently, computer application technology and information technology has become an important measure criterion of corporate strength, therefore, enterprises should strengthen the construction of information technology and computer application technology. This paper analyzes the practical significance, problems and corresponding measures of computer application technology and information technology,.

\section{PRACTICAL SIGNIFICANCE OF THE CONSTRUCTION} OF ENTERPRISE COMPUTER TECHNOLOGY AND INFORMATION TECHNOLOGY

With the rapid socio-economic development, enterprises face more and more intense competition. Competitiveness can determine whether an enterprise can win in the future. Enterprise computer application technology and information technology can improve the competitiveness of enterprises, promoting enterprise's development. Thus, enterprise computer application technology and information technology has very important practical significance.

Firstly, computer application technology and information technology can enhance the communication with the outside. The communication with the outside means enterprises can communicate and transmit information with the outside environment, such as the competitors, business partners, government and markets. With the extensive application of information technology, people have entered the information society, to country, business and people, information is a kind of wealth, no matter which country, which companies, or which person have received a first-hand information, they will grasp the 
initiative and the commanding heights of wealth, which is very important for countries, companies and individuals. Particularly in business, as long as the enterprise obtains information, it will occupy the development opportunities. Therefore, in order to develop, an enterprise should recognize the importance of computer application technology and information technology. The use of computer technology can enhance information exchange and communication with the outside world, to obtain the latest industry trends and information.

Secondly, computer application technology and information technology can also strengthen the transmission of information and communication within the enterprise. A fast-growing enterprise must need a lot of information, and will have a lot of information activities every day. If the internal information exchange is not smooth or timely, the implementation of the internal decision-making and delivery of instructions will be hindered from the microscopic view, which will not only affect the daily operations of enterprises, but also reduce the efficiency of enterprises. And if an enterprise has advanced computer application technology and sufficient information technology construction, it will strengthen the internal communications, improving the efficiency of enterprises and promoting the comprehensive development of enterprises.

\section{OVER VIEW OF ENTERPRISE COMPUTER} APPLICATION TECHNOLOGY AND INFORMATION TECHNOLOGY

Enterprise computer application technology and information technology refers to the process using the computer technology and network technology and other modern technologies to perform in-depth information resource development and widespread use, to improve the level and efficiency of production, management, operation and decision-making, thereby enhancing the competitiveness and economic efficiency of an enterprise. This is because with the application of information technology and computer application technology, companies are able to get a lot of information to process, taking use of these technologies and information for enterprise production management and products research to make the management more reasonable and scientific and the production process can effectively save production costs, thereby improving the company's cash flow, material flow, personnel flow and information flow, which generates impact for the traditional management model. At the same time of accelerating modern business model, the management philosophy is promoted and competitive strategy is innovated, strengthening the comprehensive competitiveness of enterprises. System analysis architecture is shown in Fig.1. 


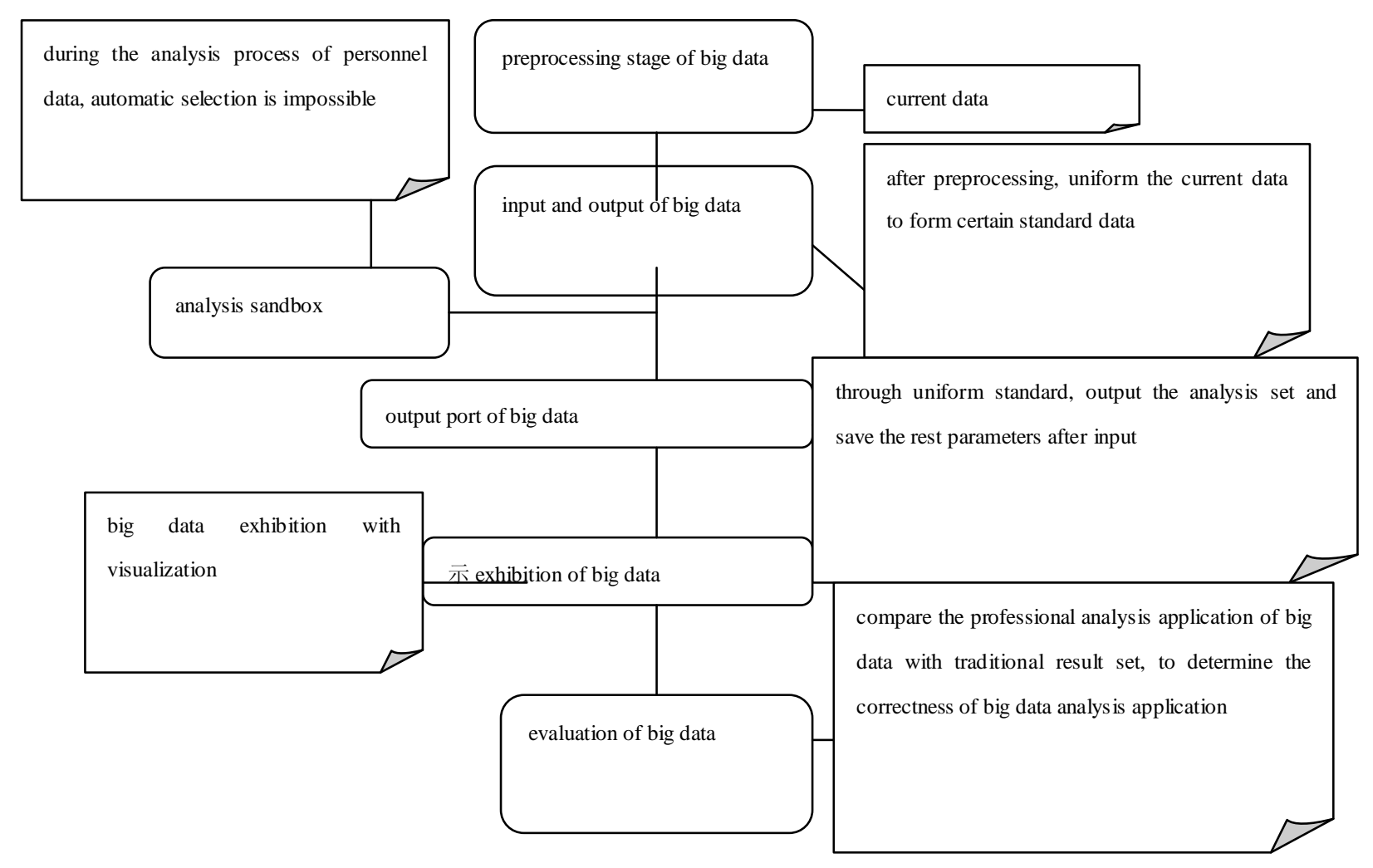

Figure 1. Analysis structure of the system

\section{THE EXISTING PROBLEMS OF ENTERPRISE}

\section{COMPUTER APPLICATION TECHNOLOGY AND INFORMATION} TECHNOLOGY

\section{A. Not complete}

Although most companies have recognized the importance of information technology and computer application technology, there are still a small part of the businesses having wrong understanding for information technology and computer application technology. These companies have the following misconceptions. Firstly, some companies do not configure the computer facilities, nor information technology, computer application technology is considered to be dispensable. So they believe that even without the computer application technology, business still develops well. Secondly, some enterprises have applied computer technologies, but not correctly applied, they didn't find the significance of computer application technology and information.

\section{B. Lack of professional staff}

Many companies recognize the importance of information technology and computer application technology for the enterprise, and also put the information technology construction and computer application technology on the key position. However, due to lack of professional talents and computer information technology personnel, it leads to the stagnation of the development of enterprise information construction and computer application technology, to a certain extent, limit the development of enterprises.

\section{Lack of investment}

Some companies do not pay attention to information technology and computer application technology, and did not invest money to build. While some companies pay attention to information technology and computer application technology, but because their staffs only have technical expertise without management experience, the knowledge of software and hardware is not in place. Software and hardware development are ignored, and the 
enterprises do not invest corresponding development funds. In addition, information technology also needs a lot of money, but often it's often ignored by companies

\section{CONCLUSION}

The rapid development of big data within computer application technology needs to improve the operator's ability to adapt to the bandwidth. Computer application technology not only brings enormous business opportunities and economic interests to network operators, but also brings unprecedented challenges.

Enterprise information technology and computer application technology is very important for the enterprise, therefore, enterprises should take it seriously. But now, there are companies having problems in the information technology and computer application technology, such as awareness of the problem, the problem of talent and funding issues. In this regard, enterprises should strengthen the information technology and computer application technology awareness, strengthen personnel training, and increase capital investment, thereby strengthening the construction of information technology and computer application technology for enterprises.

\section{REFERENCES}

[1] Liao R H, Ying H U, Yong-Fan L I, et al. College Computer Application Test System Based on B/S and C/S[J]. Journal of Hunan First Normal University, 2009.

[2] Liu G, Chen W. Computer Application in Chemical Engineering[J]. Guangdong Chemical Industry, 2012.

[3] Card S, Henderson A, Card S, et al. CATALOGUES: A METAPHOR FOR COMPUTER APPLICATION DELIVERY[J]. Human-computer Interaction-interact, 1987:959-964.

[4] Yu L U, Zhang X H. Double Main Model in The Practical Courses of Computer Application[J]. Computer Knowledge \& Technology, 2013.

[5] Li-Ping L I, Yan Y U, Sheng L Y. Research on Computer Application Personnel Training Pattern[J]. Computer Education, 2010.

[6] Kennedy T, Hoffmann A G. On-Line Digital Computer Application Techniques for Complex Electric System Dispatch[J]. Power Apparatus \& Systems IEEE Transactions on, 1968, pas-87(1):67 73.

[7] Vinoski S. It's just a mapping problem [computer application adaptation][J]. Internet Computing IEEE, 2003, 7(3):88-90.

[8] Vinoski S. It's just a mapping problem [computer application adaptation][J]. IEEE Internet Computing, 2003, 7(3):88-90.

[9] Zhao R L, Ping L I. Discussion on Computer Application Ability Building in Tourism Management[J]. Modern Computer, 2012.

[10] Zhang J H, Yang H J. Computer Application in The Research of Green Chemistry[J]. Heibei Chemical Engineering \& Industry, 2001.

[11] Smith C E, Roth A C, Milner S M. Palm-Top Computer Application for Fluid Resuscitation in Burns: 269.[J]. Journal of Burn Care \& Research, 2001, 22.

[12] Smith, C. E., Roth, A. C., \& Milner, S. M. (2001). Palm-top computer application for fluid resuscitation in burns: 269.. Journal of Burn Care \& Research, 22. 